\title{
Gloquídio de Diplodon martensi (lhering) (Mollusca, Bivalvia, Hyriidae) e seu ciclo parasitário
}

\author{
Maria Cristina Dreher Mansur ${ }^{1}$
}

\begin{abstract}
The glochidium of Diplodon martensi (Ihering) (Mollusca, Bivalvia, Hyriidae) and its parasitic cycle. Conchological and anatomical studies of the glochidium of Diplodon martensi (Ihering, 1893) were performed on samples collected in a small river, tributary from the Cai River, that belong to the Jacui River sub-basin in south-eastern Brazil. The parasitic development of the glochidium was observed in laboratory on a small cichlid fish Gymnogeophagus gymnogenys (Hensel, 1870).

KEY WORDS. Mollusca, Bivalvia, Unionoida, Hyriidae, Diplodon martensi, glochidium parasitic cicle
\end{abstract}

Os moluscos bivalves de água doce da superfamília Unionoidea apresentam uma larva chamada gloquídio que geralmente parasita os peixes. Estes, por sua vez auxiliam o molusco na dispersão rio acima, em direção às águas mais interiores. $\mathrm{Na}$ passagem do peixe, o bivalve contendo gloquídios maduros, libera as larvas que se tornam temporariamente planctônicas. Estas se aderem às escamas, nadadeiras ou brânquias do peixe, tornando-se ectoparasitos temporários. Onde a larva se fixa forma-se um cisto, dentro do qual o gloquídio completa seu desenvolvimento, até a pós-larva. Este período de parasitismo, que dura de 10 a 30 dias, é geralmente condicionado às épocas de águas altas na primavera, quando ocorre o fenômeno conhecido pelos nativos como "piracema" (MANSUR \& OLIVEIRA DA SILVA 1999).

Os gloquídios das espécies de naiades sul-americanas (Hyriidae) tem afinidades morfológicas com as espécies australianas e são distintos das demais espécies de Unionoidea que vivem na região Holártica (PARODIZ \& BONETTO 1963; BONETTO et al. 1986). Suas características auxiliam na identificação e classificação deste difícil grupo de moluscos, cujos indivíduos jovens e adultos raramente apresentam critérios diagnósticos inter específicos.

Segundo ORTMANN (1921) e os autores citados anteriormente, entre os Hyriidae conhecem-se fundamentalmente dois tipos de gloquídios: -Os portadores de dentes, que apresentam desenvolvimento parasitário no peixe, onde se forma um cisto e dentro do qual o gloquídio completa seu desenvolvimento até a pós-larva, e os que não possuem dentes e apresentam um desenvolvimento completo, dentro dos ovos que permanecem nas bolsas incubadoras chamadas marsúpios, até a pós-larva. Estes últimos não utilizam o peixe nem para seu desenvolvimento, nem para sua dispersão.

1) Museu de Ciências e Tecnologia, Pontifícia Universidade Católica do Rio Grande do Sul. Avenida Ipiranga 6681, prédio 40, 90619-900 Porto Alegre, Rio Grande do Sul, Brasil. Bolsista do CNPq.

E-mail: mcmansur@pucrs.br

Revta bras. Zool. 16 (Supl. 2): 185 - 194. 1999 
Quanto a relação hospedeiro-parasito, existe uma especificidade entre ambos. Poucos dados existem na literatura sobre as espécies de peixe que apresentam afinidade imunológica, permitindo o desenvolvimento do gloquídio. BONETTO \& EzCURRA (1963) mencionaram as espécies de peixes Prochilodus platensis Holmberg, 11891, Serrasalmus sp., Astyanax fasciatus (Cuvier, 1819), Geophagus sp., Aequidens sp., Schizodon faciatum Spix \& Agassiz, 1829 e Charax stenopterus (Cope, 1894), para o molusco Diplodon delodontus (Lamarck, 1819). Prochilodus platensis $[=$ P. lineatus (Valenciènnes, 1847)] e Hoplias malabaricus (Bloch, 1794) para $D$. parallelopipedon (Lea, 1834) (BonETTO 1955) e D. parodizi Bonetto, 1962, espécie inicialmente identificada por BONETTO $(1954,1955)$ como D. burroughianus (Lea, 1834) e ou D. charruanus (Orbigny, 1835).

A obra de BONETTO (1954) é a primeira e única que mostra um pequeno desenho de quatro cistos parasitários formados por gloquídios de uma espécie de Hyriidae do Rio Paraná, na extremidade distal de um filamento branquial do peixe "traíra" Hoplias malabaricus. O autor cita que as larvas infestadas artificialmente se fixaram no tecido do peixe, originando-se um cisto para cada larva. Esta evoluiu, completando seu desenvolvimento ao cabo de 10 a 20 dias. Soltou-se então do cisto, apresentando o aspecto de um bivalve jovem. Mencionou que nas bordas das valvas se formaram duas ou tres bandas e que no total a larva cresceu $0,03 \mathrm{~mm}$ de comprimento e de altura. Não há dados sobre outras transformações da larva encistada, apenas que os dentes gloquidianos ainda pendiam para fora das valvas do "jovem" recem eclodido e que desapareceram em poucos dias. Naquela ocasião (BONETTO 1954), a larva foi identificada como pertencente a Diplodon charruanus. Mais tarde BONETTO (1962a) reconheceu esta espécie como nova e a descreveu como D. parodizi Bonetto, 1962.

BONETTO \& EZCURRA (1963) descrevem o desenvolvimetno larval de $D$. delodontus delodontus (Lam.) sobre as várias espécies de peixes mencionadas acima. Houve uma maior ocorrência de larvas sobre Astyanax fasciatus. Os gloquídios se fixaram naturalmente sobre as aletas ou guelras dos peixes confinados em aquários juntamente com moluscos contendo embriões maduros ou foram infestados artificialmente. Nos primeiros dias a larva fixou-se ao peixe somente com os dentes. Depois de três dias observaram a formação de um cisto a partir de uma modificação do tecido do peixe, que acabou envolvendo completamente o gloquídio a partir do sexto dia. Entre 25 e 30 dias completou-se o desenvolvimento parasitário, quando romperam-se os cistos, e desprenderam-se os primeiros jovens.

Em toda a literatura pesquisada que menciona a larvas de moluscos bivalves de água doce de Hyriidae, não existem mais dados sobre a fase parasitária de gloquídios da América do Sul, a não ser sobre o número de dias de parasitismo de algumas espécies. Também não existem dados sobre a vida embrionária e transformações ocorridas dentro do ovo das larvas que não apresentam vida parasitária e que permanecem incubadas dentro dos marsúpios até eclodirem como pós-larvas.

Objetiva-se contribuir para o conhecimento da morfologia e sistemática dos moluscos bivalves de água doce da América do Sul. Apesar destes moluscos terem sua vida e dispersão intimamente relacionada aos peixes e mesmo desempenhando um papel de extrema importância ecológica na vida de nossos ambientes límnicos, por serem ativos filtradores, são pouco conhecidos em nosso meio. 


\section{MATERIAL E MÉTODOS}

Os exemplares adultos de Diplodon martensi (Ihering, 1893) foram coletados no arroio Bom Jardim que apresenta uma extensão aproximada de $12,5 \mathrm{Km}$ a partir de sua foz situada na margem direita do rio Caí em seu curso inferior. Limita, em parte, os municípios de Triunfo e Montenegro, correndo de Oeste para Leste. Neste Arroio a Estação de Coleta escolhida dista mais ou menos 2,5 Km da foz e se situa a partir de 6 metros à montante da ponte que cruza o Arroio (latitude $29^{\circ} 50^{\prime} 01^{\prime \prime S}$ e longitude $051^{\circ} 20^{\prime} 21^{\prime \prime} \mathrm{W}$ ) numa extensão de $16 \mathrm{~m}$ ao longo do leito.

No arroio Bom Jardim as coletas foram mensais, durante o período de janeiro de 1980 a fevereiro de 1981, a fim de estabelecer a época de eliminação dos gloquídios. Os exemplares de $D$. martensi foram localizados pelo tato e capturados com as mãos. Amostras dos moluscos coletados foram transportados ao laboratório dentro de caixas ou sacos plásticos com alguma água do local, para conservar a umidade. Após a coleta, os animais foram deixados em repouso até o dia seguinte. Abriu-se entre as valvas uma fresta ventral, introduzindo-se uma cunha de madeira redonda, evitando não danificar as bordas do manto. Depois forçou-se um afastamento lento e um pouco maior das valvas com o auxílio dos dedos. Com um pincel fino afastou-se o pé do molusco até poder observar a demibranquia interna onde se localiza o marsúpio. Somente após a evidência da existência de gloquídios maduros, o animal foi sacrificado.

Parte dos gloquídios maduros foram montados em lâminas permanentes. As larvas foram retiradas de parte dos marsúpios do indivíduo "mãe" e anestesiadas com cristais de Mentol durante 48 horas. Os tecidos foram removidos com hipoclorito de sódio comercial (oito gotas para $10 \mathrm{ml}$ de água de ionizada por cinco minutos). As valvas foram limpas por maceração em água deionizada em tubos de ensaio, durante dois dias, com a troca freqüente do líquido, auxiliada por pipeta. Desidratação por série de álcool etílico até $96^{\circ}$ G.L. e ao final por dois banhos de álcool isopropílico e montagem em lâminas permanentes com Entelan. Mais detalhes sobre estes procedimentos e a conquiliometria das valvas gloquidianas constam em MANSUR \& CAMPOS-VELHO (1990). Ao todo foram medidas 40 larvas. Algumas larvas foram observadas vivas ao microscópio biológico, em diferentes aumentos. Para evidenciar a organização interna utilizou-se algumas gotas de Azul de Metileno diluído a $1 / 1000$.

Coletou-se pequenos peixes ciclídios, vulgarmente conhecidos por "cará", Gymnogeophagus gymnogenys (Hensel, 1870) (entre 4 e $5 \mathrm{~cm}$ ) no lago do Jardim Botânico de Porto Alegre, os quais foram mantidos em laboratório num aquário de $60 \times 30 \times 40 \mathrm{~cm}$.

Através do exame dos peixes, constatou-se a inexistência de infestação anterior por larva de moluscos.

No momento em que foi constatada a presença de gloquídios maduros e ativos nas brânquias do molusco $D$. martensi, procedeu-se a infestação artificial. Tres peixinhos foram retirados do aquário e transferidos para outro menor $(20 \times 10$ x $12 \mathrm{~cm}$ ), aerizado. Uma porção do marsúpio contendo os gloquídios foi esfregada pelo corpo de cada peixe e o restante do marsúpio espalhado pela água do aquário 
menor. Os peixes permaneceram confinados neste aquário aproximadamente quatro horas e a seguir recolocados no aquário maior, e observados diariamente. No $5^{\circ}$, $18^{\circ}, 24^{\circ}, 30^{\circ}$ e $33^{\circ}$ dia, um quisto foi retirado de um dos exemplares de peixe, alternadamente, levado ao microscópio e medido.

Não foram observadas as guelras dos peixes durante o período de infestação.

As amostras dos moluscos coletados e as lâminas preparadas foram depositadas na coleção científica do Museu de Ciências Naturais da Fundação Zoobotânica do Rio Grande do Sul.

\section{RESULTADOS}

\section{Descrição das valvas gloquidianas}

Os gloquídios de D. martensi apresentam um dente em forma de "S", articulado na base e inserido internamente junto a ponta ventral de cada valva. Este dente termina em tres cúspides grupadas, sendo a central mais alongada e translúcida que as duas laterais (Figs 1-3). As valvas são articuladas na linha dorsal e tem o contorno sub-triangular semelhante aos dos gloquídios parasitos descritos por ORTMANN (1921), BONETTO (1960a,b, 1961a,b, 1962a,b), BONETTO \& EZCURRA (1963, 1965) e ALVARENGA \& RICCI (1979).

A superfície externa é granulada, lembrando o aspecto da casca de ovo em aumentos de 100 e 400 vezes. É perfurada por poros minúsculos visíveis em aumento de 400 vezes. Cada poro apresenta um diâmetro aproximado de um micrômetro. Toda a borda de cada valva é circundada por uma cinta que se destaca da superfície geral, por ser lisa (Figs 1-3).

Os 40 gloquídios medidos de $D$. martensi apresentam o comprimento com variação de $0,28 \mathrm{~mm}$ a $0,32 \mathrm{~mm}$, a maior frequência e a média igual a $0,29 \mathrm{~mm}$; a altura de $0,24 \mathrm{~mm}$ a $0,28 \mathrm{~mm}$ com a maior frequência e a média igual a $0,25 \mathrm{~mm}$; o comprimento da linha dorsal de $0,20 \mathrm{~mm}$ a $0,23 \mathrm{~mm}$ com a maior frequência em $0,21 \mathrm{~mm}$ e $0,22 \mathrm{~mm}$ e a média igual a $0,21 \mathrm{~mm}$; o deslocamento da ponta ventral com a variação de $0,02 \mathrm{~mm}$ a $0,05 \mathrm{~mm}$, sendo a maior frequência $0,04 \mathrm{~mm}$ e a média $0,03 \mathrm{~mm}$; o ângulo de obliqüidade da ponta ventral em relação ao centro da linha dorsal variando de $12^{\circ}$ a $19^{\circ}$, com a maior freqüência em $15^{\circ}$ e a média em $15,52^{\circ}$. O comprimento do dente atingiu de $0,10 \mathrm{~mm}$ a $0,11 \mathrm{~mm}$.

\section{Descrição da anatomia gloquidiana}

Os gloquídios de D. martensi (Figs 1-3) apresentam um músculo adutor central, um órgão ciliado posterior e um longo filamento anterior. Este atinge aproximadamente quatro vezes o comprimento da valva gloquidiana e, até ser exteriorizado, permanece enrolado dando duas voltas completas no interior do gloquídio. Próximo a base do filamento se encontra um par de cirros sensitivos termo usado por BonETTO (1962a) - que coram fortemente com Azul de Metileno. Estes cirros tem o formato de acúleo com a base arredondada (Fig. 1). Na face interna de cada dente gloquidiano existe um tufo de cílios sensitivos (Fig. 2). O restante da cavidade palial do gloquídio se apresenta revestida por células grandes - fagocitárias segundo DAWYDOFF (1928) ou do manto segundo HARMS (1909) -, formando um tecido de aspecto esponjoso. 


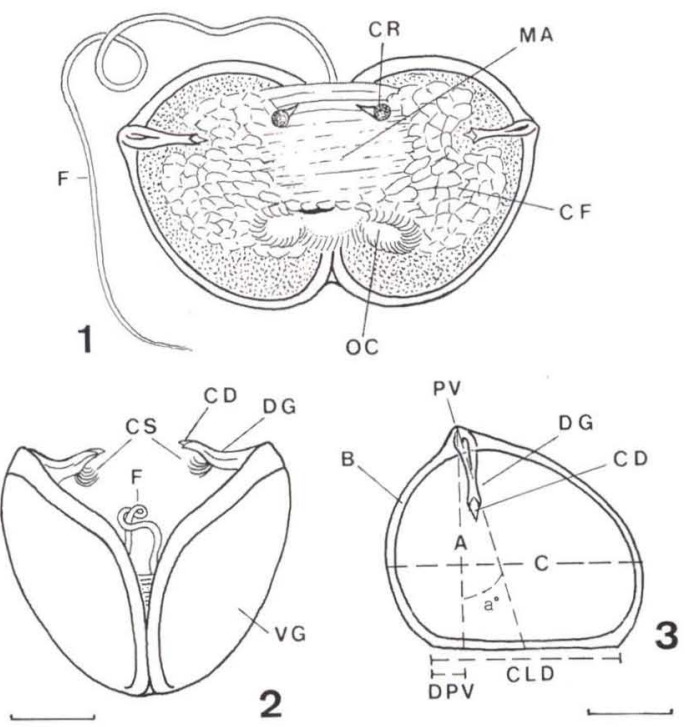

Figs 1-3. Gloquídio de Diplodon martensi. (1) Organizaçăo interna do gloquídio parasito em vista ventral; (2) vista frontal do gloquídio; (3) vista lateral. (A) Altura, ( $a^{\circ}$ ) ângulo, (B) borda, (C) comprimento, (CD) cúspides do dente gloquidiano (CLD) comprimento da linha dorsal, (CF) células fagocitárias, (CR) cirros sensitivos, (CS) cílios sensitivos, (DG) dente gloquidiano, (DPV) deslocamento da ponta ventral em relação ao meio da linha dorsal, (F) filamento ou flagelo, (MA) músculo adutor, (OC) órgão ciliar posterior, (PV) ponta ventral, (VG) valva gloquidiana. Barra 0,1 mm.

\section{Infestação artificial e ciclo da larva parasita}

No final do inverno foram constatados indivíduos de D. martensi grávidos, ou seja, contendo embriões em seus marsúpios. No entanto os gloquídios maduros só apareceram na primavera, no período de muita chuva. O indivíduo com gloquídios maduros, utilizado no experimento, foi coletado em 28 de setembro de 1980.

A infestação artificial por gloquídios de $D$. martensi em três exemplares do peixe "cara" Gymnogeophagus gymnogenys (Hensel, 1870) foi positiva.

Os peixes foram infestados no dia seguinte ao da coleta do exemplar adulto contendo gloquídios maduros. Os gloquídios que aderiram foram em número de 26, 9 e 8 respectivamente, para cada peixe. Formaram-se quistos nas nadadeiras dorsal, caudal e ventral dos peixes. Inclusive um quisto se formou na cabeça, na parte superior do olho de um deles.

A observação do gloquídio no quinto dia de vida parasitária (Fig. 4), revelou que, apesar de totalmente recoberto pela pele do peixe, pode ser visto por transparência. Não houve crescimento externo do gloquídio e internamente surgiram áreas mais densas e escuras e o dente permaneceu visível.

No décimo oitavo dia (Fig. 5), o cisto se apresentou mais espesso, tornandose difícil visualizar o gloquídio por transparência. $\mathrm{O}$ dente continuou presente e não surgiram evidências de crescimento externo. 

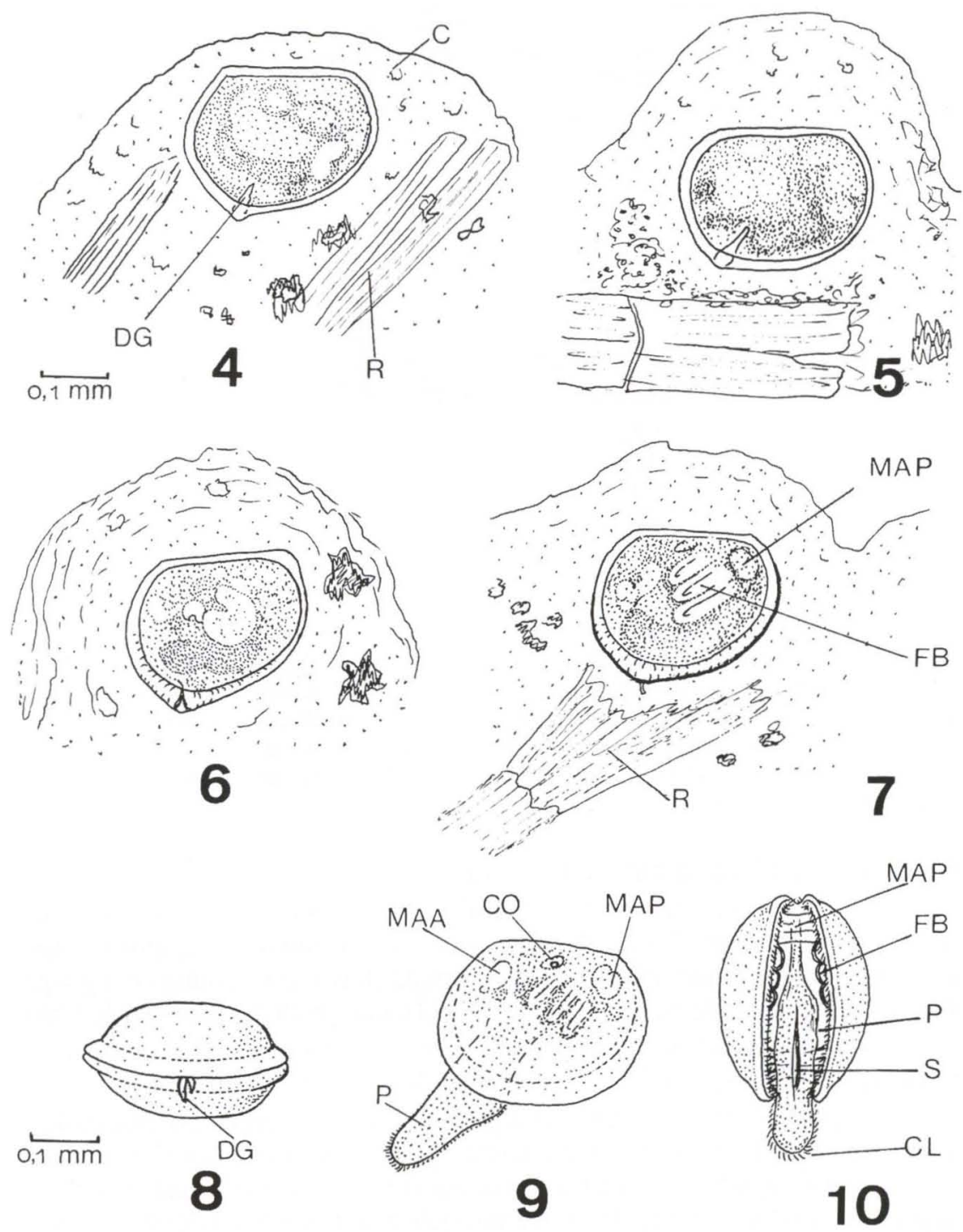

Figs 4-10. (4-7) Desenvolvimento parasitário do gloquídio de Diplodon martensi: (4) no $5^{\circ}$ dia, em cisto do peixe; (5) no $18^{\circ} \mathrm{dia}$; (6) no $24^{\circ}$ dia; (7) no $30^{\circ}$ dia de vida parasitária. (8-10) Pós-larva de $D$. martensi no primeiro dia de vida livre: (8) vista ventral, com as valvas cerradas; (9) vista lateral, animal distendido; (10) vista ventral, animal distendido. (C) Cisto do peixe, $(\mathrm{CL})$ cilios; (CO) coração; (DG) dente gloquidiano, (FB) filamentos branquiais; (MAA) músculo adutor anterior; (MAP) músculo adutor posterior, $(P)$ pé, $(R)$ raio da aleta do peixe, $(S)$ sulco ventral do pé. 
No vigésimo quarto dia o quisto se apresentou mais denso (Fig. 6). Foi necessário rompê-lo para visualizar o gloquídio. $\mathrm{O}$ dente se reduziu a resquícios e surgiu um leve espessamento nas bordas ventrais das valvas gloquidianas.

No trigésimo dia (Fig. 7) observou-se a presença de 3 filamentos branquiais internos de cada lado e um espessamento um pouco mais acentuado nas bordas ventrais das valvas.

Os gloquídios enquistados eclodiram a partir do $30^{\circ}$ dia até o $33^{\circ}$ dia de vida parasitária. O último gloquídio eclodiu durante a noite do $32^{\circ}$ ao $33^{\circ}$ dia.

Comparando as valvas gloquidianas antes da fase parasitária com o jovem recém eclodido, percebeu-se que houve um crescimento das valvas durante a fase parasitária. Este crescimento foi promovido por um espessamento das bordas livres que cingem as valvas e resultou num acréscimo de aproximadamente $0,05 \mathrm{~mm}$ no comprimento e $0,02 \mathrm{~mm}$ em altura total. Resquícios dos dentes gloquidianos pendiam para fora das valvas (Fig. 8).

\section{A pós-larva}

No primeiro dia de vida livre, apresentou um comprimento de $0,33 \mathrm{~mm}$, um pé ciliado com sulco longitudinal ventral, as bordas do manto com longos cílios e três filamentos branquiais de cada lado (Fig. 10). Foi possível observar o coração e os músculos adutores por transparência (Fig. 9). Vestígios dos dentes ainda pendiam da ponta ventral para o lado externo, e ao serem tocadas cairam (Fig. 8). Neste momento a pós-larva perde os últimos vestígios larvais, apresentando as características de um jovem minúsculo que se locomove livremente sobre o solo com a ajuda do pé (Fig. 10). Não foi observada a formação de bisso no sulco ventral do pé. É possivel que o sulco desapareça gradativamente, a medida que o animal for crescendo, uma vez que os jovens mais desenvolvidos não apresentam o sulco ventral.

\section{DISCUSSÃO}

Frente as dimensões apresentadas por ORTMANN (1921); BONETTO (1960a,b, 1961a,b, 1962a,b); BONETTO \& EzCURRA $(1962,1963,1965)$ e ALVARENGA \& RICCI (1979) para os gloquídios até o presente descritos, pode-se afirmar que os de D. martensi aproximam-se proporcionalmente aos maiores conhecidos, ou seja, os de $D$. paulista Ihering, 1893, cujas medidas são: comprimento $0,32 \mathrm{~mm}$, altura de $0,26 \mathrm{~mm}$ a $0,27 \mathrm{~mm}$, comprimento da linha dorsal $0,22 \mathrm{~mm}$, o deslocamento da ponta ventral $0,03 \mathrm{~mm}$, o ângulo de obliqüidade $18^{\circ}$ a $19^{\circ}$ e comprimento do dente $0,10 \mathrm{~mm}$. Os gloquídios de $D$. martensi apresentam altura considerável em relação ao comprimento, porém são mais baixos que $D$. piceus (Lea, 1860), cujo comprimento e altura estão em torno de $0,28 \mathrm{~mm}$ a $0,29 \mathrm{~mm}$. São proporcionalmente um pouco maiores que os gloquídios de $D$. besckeanus (Dunker, 1849) e apesar de atingirem o comprimento de $D$. multistriatus (Lea, 1831) e $D$. decipiens Ortmann, 1921 estes são mais baixos apresentando respectivamente $0,22 \mathrm{~mm}$ e $0,24 \mathrm{~mm}$ de altura. Os gloquídios de $D$. imitator Ortmann, 1921 com o comprimento e altura em torno de $0,27 \mathrm{~mm}$ a $0,28 \mathrm{~mm}$ e o dente com $0,09 \mathrm{~mm}$ de comprimento, aproximam-se das larvas dos exemplares de $D$. martensi quanto a altura, porém são menos alongados do que estes. 
A organização interna do gloquídio de $D$. martensi assemelha-se de uma maneira geral à dos gloquídios da família Unionidae descritos por HARMS (1909) e DAWYDOFF (1928). Entre os gloquídios sul americanos já descritos, assemelha-se mais ao de $D$. parodizi Bonetto, 1962 figurado em PAROdIZ \& BonETTO (1963), que também apresenta apenas um par de tufos de cílios sensitivos sob os dentes. Diplodon delodontus delodontus conforme BONETTO \& EZCURRA (1965) apresenta dois pares de tufos de cílios sesitivos.

Observou-se que o período de eliminação dos gloquídios de D. martensi coincide com o período em que as águas do arroio Bom Jardim atingem um nível alto na primavera. KLEEREKOPER (1955) observou que é neste período de "águas altas", que ocorre a migração dos peixes para as águas das depressões mais interiores, subindo dos arroios e lagos em direção aos banhados.

A larva de $D$. charruanus $(=D$. parodizi $)$ infestada artificialmente por BONETTO (1954), encistou-se na extremidade distal de um filamento branquial do peixe "traira" Hoplias malabaricus, completando seu desenvolvimento em 10 a 20 dias, ou seja, num período mais curto que o de D. martensi. Apresentou um crescimento maior tanto na altura como na largura, com duas ou mais bandas nas bordas que também não foram observadas em D. martensi. BONETTO (1954) ainda menciona que além da espécie acima, $D$. parallelopipedon e $D$. delodontus também se desenvolveram sobre tecidos de determinados peixes e que não conseguiu infestação positiva em peixes que teve a disposição (ver relação de peixes na introdução), com gloquídios de D. trifidus. O mesmo autor especifica em termos de tecidos dos peixes, apenas os filamentos branquiais, onde a infestação foi positiva para D. parallelopipedon e D. parodizi. Já mais adiante BONETTO \& EZCURRA (1963) mencionam a adesão das larvas de $D$. delodontus delodontus tanto nos filamentos branquiais como na pele do peixe, em especial nas aletas. Descrevem também que houve um crescimento junto a alguns setores das valvas das larvas eclodidas entre os dias 25 e 27 e que as larvas liberadas no $30^{\circ}$ dia mostraram um crescimento maior, formando nítidas bandas de crescimento ao redor da margem livre das valvas. Estas bandas de crescimento não foram observadas nas pós-larvas recem eclodidas de $D$. martensi. Houve apenas um espessamento juntos as bordas livres das valvas.

AGRADECIMENTOS. À Ines Ezcurra de Drago do Instituto Nacional de Limnologia, Santa Fé, Argentina, que nos ensinou a metodologia de infestação artificial de gloquidios sobre peixes. Às colegas, ME Karin M. Grosser do Museu de Ciências Naturais da Fundação Zoobotânica do Rio Grande do Sul, pela identificação do peixe "cará"; Lília Maria Anflor de Oliveira e Jane E. Marques de Almeida Caon, do mesmo Museu, pelo auxílio nas coletas.

\section{REFERÊNCIAS BIBLIOGRÁFICAS}

AlvarenGA, L.C.F. \& C.N. RicCI. 1979. Contribuição ao conhecimento dos gloquídios do gênero Diplodon Spix, 1827: D. besckeanus (Dunker, 1849) (Bivalvia; Unionoidea; Hyriidae). Publ. Avuls Fund. Zoobotânica Rio Grande do Sul, Porto Alegre, 4: 33-38.

Revta bras. Zool. 16 (Supl. 2): 185 - 194, 1999 
BonetTo, A.A. 1954. Nayades del Rio Paraná. El gênero Diplodon en el Biotopo isleño del Parana medio y inferior. Publ. Técn., Secret. de Agricultura, Ganaderia y Industrias, Santa Fé (62): 1-56.

. 1955. Acerca de las formas larvales de Mutelidae Ortmann. Jornadas

Icticas, Direcc. Gral. Inv. Fom. Agr. Ganad., Santa Fé, 1 (1): 1-8

.1960a. Sobre algunas nuevas formas larvales de Hyriinae Ortmann. Actas

y Trabajos Congreso Sudamericano de Zoologia, La Plata, 2 (3): 33-41.

- 1960b. Contribuición al conocimientes de las glochidias del género Diplodon y su aplicación a los estudios sistemáticos. Actas y Trabajos Congr.

Sudamericano de Zoologia, La Plata, 2 (3): 43-59.

. 1961a. Investigaciones acerca de las formas larvales en el género Diplodon y su aplicación a los estudios sistemáticos. Dir. Gral. Rec. Nat., Min Agr. Ganad. Publ. Tecn., Santa Fé: 3-48.

- 1961b. Nuevas notas sobre formas larvales de Nayades Sud y Centroamericanas. Physis, Buenos Aires, 21 (62): 332-335.

. 1962a. Especies nuevas y poco conocidas de nayades del sistema del Rio de La Plata y otras cuencas proximas. Publ. Técnica, Direcc. Gral de Recursos Naturales, Reunion de trabajos y Comunicaciones de Ciencias Naturales y Geografia del Litoral Argentino, Santa Fé, (8): 213-144.

- 1962b. Notas sobre Diplodon charruanus (Orb.) y Diplodon rhuacoicus

(Orb.). Publ. Técnica, Direcc. Gral de Recursos Naturales, Reunion de trabajos y Comunicaciones de Ciencias Naturales y Geografia del Litoral Argentino, Santa Fé (10): 35-44.

BonetTo, A.A. \& I.D. EzcurRA. 1962. Algunas variaciones de Diplodon charruanus (Orb.). Anales Mus. "F. Ameghino", Santa Fé, 1 (3): 31-373.

BonetTo, A.A. \& I.D. EzcurRA. 1963. Notas malacologicas. I. Physis, Buenos Aires, 24 (67): 17-21.

1965. Estudio comparado de las formas larvales de Mutelidae Ortmann y su significacion sistemática y zoogeográfica (Mollusca, Pelecypoda). An. Congr. Latino-Americ. Zool., São Paulo, 2 (2): 56-71.

BonetTo, A.A.; M.P. TASSARA \& A. Rumi. 1986. Australis n. subgen. de Diplodon Spix (Bivalvia, Unionacea) y posibles relaciones con Hyriidae australianos. Bol. Soc. Biol., Concepcion, 57: 55-61.

DAWIDOFF, C. 1928. Traité d' Embriologie comparée des Invertebrés. Masson, Paris, 930p.

HARMS, W. 1909. Postembryonale Entwicklungsgeschichte der Unioniden. Zoologische Jahrbücher, Jena, 28 (2): 325-85.

KLEEREKOPER, H. 1955. Limnological observations in notheastern Rio Grande do Sul, Brazil I. Archiv für Hydrobiologie, Stuttgart, 50 (3-4): 553-67.

MANSUR, M.C.D. \& N.M.R. CAMPos-VELho. 1990. Técnicas para o estudo dos gloquídios de Hyriidae (Mollusca, Bivalvia, Unionoida). Acta Biol. Leopoldensia, São Leopoldo, 12 (1): 5-18.

MANSUR, M.C.D. \& M.G. Oliveira DA Silva. 1999. Description of glochidia of five species of freshwater mussels (Hyriidae: Unionoidea) from South America. Malacologia, Philadelphia, 41 (2): 1-9.

ORTMANN, A. E. 1921. South American Naiades; a contribution to the knowledge 
of the freshwater mussels of South America. Memoirs of the Carnegie Museum, Pittsburgh, 8 (3): 451-684.

PARODIZ, J.J. \& A.A. BONETTO. 1963. Taxonomy and zoogeographic relationships of the South American naiades (Pelecypoda: Unionacea and Mutelacea).

Malacologia 1 (2): 179-213.

Recebido em 12.XI.1998; aceito em 24. XI.1999. 